\title{
Limitations of measurement of transdiaphragmatic pressure in detecting diaphragmatic weakness
}

\author{
ANDRÉ DE TROYER AND MARC ESTENNE \\ From the Chest Service, Erasme University Hospital, Brussels School of Medicine, Brussels, Belgium
}

\begin{abstract}
Intrathoracic (oesophageal), intra-abdominal (gastric), and transdiaphragmatic (Pdi) pressures were studied in 20 untrained, healthy subjects during a full inspiration and repeated maximal static inspiratory efforts. The pattern of pressure generation during these two types of respiratory manoeuvre was highly reproducible in each subject. By contrast, it varied over a wide range among individuals. In particular a substantial number of subjects naturally had a strong recruitment of their intercostal and accessory muscles and thus, low Pdi values, during both slowly performed and forceful inspiratory manoeuvres. These observations make it clear that Pdi values, as usually obtained, are commonly open to misinterpretation. For this approach to ensure a reliable assessment of diaphragmatic function and detect diaphragm weakness adequately, it appears essential either to monitor the abdominothoracic configuration or to standardise the pattern of respiratory muscle contraction.
\end{abstract}

In 1960 Agostoni and $\mathrm{Rahn}^{1}$ introduced the simultaneous measurement of oesophageal and gastric pressures in order to analyse the relative contributions of thorax, abdomen, and diaphragm to the mechanical behaviour of the respiratory system. The differential measurement of gastric and oesophageal pressures determines the pressure developed across the diaphragm and thus, provides quantitative information concerning the behaviour of this muscle. Since its original description, this technique has been widely used by physiologists in the study of respiratory mechanics in healthy man, ${ }^{2-5}$ but only recently has been applied in the clinical field. It is claimed that measurement of transdiaphragmatic pressure is the most accurate method of assessing diaphragmatic function ${ }^{6}$; accordingly, it is increasingly performed in the evaluation of patients suspected of having compromised function. ${ }^{7-10}$ However, reference values are sparse. Furthermore, most of the normal values that have been so far published have been obtained from laboratory workers and, as stressed recently, ${ }^{9}$ it may be unreasonable to compare measurements of transdiaphragmatic pressure between patients and highly trained respiratory

Address for reprint requests: Dr A De Troyer, Meakins-Christie Laboratories, McGill University, 3775 University Street, Montreal, Quebec, Canada H3A 2B4. physiologists.

It was our original purpose to establish normal values and to describe systematically the intrathoracic, abdominal, and transdiaphragmatic pressures at different lung volumes during a slow contraction of the inspiratory muscles-namely, a full inspiration-and during maximal static inspiratory efforts in a group of untrained, healthy subjects. We chose these two respiratory acts because they are the two most commonly used tests in assessing diaphragmatic function. ${ }^{6-10}$ During the course of the study, however, we have been much impressed by the large variation between subjects in the pattern of pressure generation during these two types of respiratory manoeuvres. The major aim of this communication is to draw attention to the drawbacks of this technique which, on our evidence, is often open to misinterpretation.

\section{Methods}

Twenty untrained subjects (10 men, 10 women), 22 to 36 years of age, were investigated. They were recruited from people working in the hospital, but they were unaware of the purpose of the study. All of them were free of respiratory or neuromuscular disease, and all had normal lung volumes. Their physical characteristics and values 
Table Physical data and respiratory function studies

\begin{tabular}{|c|c|c|c|c|c|c|c|c|}
\hline \multirow[t]{2}{*}{ Subject } & \multicolumn{2}{|c|}{ Anthropometric data } & \multicolumn{2}{|c|}{ Lung volumes } & \multicolumn{2}{|l|}{ Full inspiration } & \multicolumn{2}{|c|}{$\begin{array}{l}\text { Maximal static inspiratory } \\
\text { efforts }\end{array}$} \\
\hline & $\begin{array}{l}\text { Age } \\
\text { (vr) }\end{array}$ & $\begin{array}{l}\text { Height } \\
(\mathrm{cm})\end{array}$ & $\begin{array}{l}V C \\
(l)\end{array}$ & $\begin{array}{l}T L C \\
(l)\end{array}$ & $\begin{array}{l}\text { Pst }(l) \text { at } T L C \\
\left(\mathrm{cmH}_{2} \mathrm{O}^{*}\right)\end{array}$ & $\begin{array}{l}\text { Pdi at } T L C \\
\left(\mathrm{cmH}_{2} \mathrm{O}^{*}\right)\end{array}$ & $\begin{array}{l}\text { Ppl at } 60 \% \\
\mathrm{TLC} \\
\left(\mathrm{CmH}_{2} \mathrm{O}^{*}\right)\end{array}$ & $\begin{array}{l}\text { Pdi at } 60 \% \\
\text { TLC } \\
\left(\mathrm{cmH}_{2} \mathrm{O}^{*}\right)\end{array}$ \\
\hline \multicolumn{9}{|c|}{ Normal men } \\
\hline $\begin{array}{r}1 \\
2 \\
3 \\
4 \\
5 \\
6 \\
7 \\
8 \\
9 \\
10\end{array}$ & $\begin{array}{l}24 \\
27 \\
27 \\
27 \\
28 \\
28 \\
30 \\
30 \\
30 \\
33\end{array}$ & $\begin{array}{l}169 \\
184 \\
192 \\
173 \\
174 \\
176 \\
170 \\
180 \\
178 \\
170\end{array}$ & $\begin{array}{l}4 \cdot 90 \\
5 \cdot 10 \\
6 \cdot 75 \\
5 \cdot 10 \\
5 \cdot 85 \\
5 \cdot 25 \\
4 \cdot 25 \\
5 \cdot 90 \\
5 \cdot 85 \\
4 \cdot 75\end{array}$ & $\begin{array}{l}6 \cdot 09 \\
7 \cdot 40 \\
9 \cdot 06 \\
6 \cdot 55 \\
6 \cdot 85 \\
6 \cdot 69 \\
5 \cdot 71 \\
8 \cdot 41 \\
7 \cdot 72 \\
6 \cdot 72\end{array}$ & $\begin{array}{l}40 \cdot 0 \\
31 \cdot 9 \\
31 \cdot 2 \\
32 \cdot 9 \\
41 \cdot 3 \\
24 \cdot 5 \\
46 \cdot 7 \\
48 \cdot 0 \\
38 \cdot 6 \\
35 \cdot 0\end{array}$ & $\begin{array}{l}48 \cdot 3 \\
47 \cdot 0 \\
60 \cdot 8 \\
45 \cdot 0 \\
25 \cdot 2 \\
56 \cdot 3 \\
52 \cdot 5 \\
66 \cdot 8 \\
33 \cdot 7 \\
46 \cdot 5\end{array}$ & $\begin{array}{r}-90 \\
-95 \\
-125 \\
-64 \\
-98 \\
-81 \\
-107 \\
-120 \\
-91 \\
-126\end{array}$ & $\begin{array}{r}102 \\
121 \\
137 \\
82 \\
18 \\
112 \\
120 \\
124 \\
42 \\
130\end{array}$ \\
\hline \multicolumn{9}{|c|}{ Normal women } \\
\hline $\begin{array}{l}11 \\
12 \\
13 \\
14 \\
15 \\
16 \\
17 \\
18 \\
19 \\
20\end{array}$ & $\begin{array}{l}22 \\
23 \\
25 \\
25 \\
26 \\
26 \\
28 \\
29 \\
31 \\
36\end{array}$ & $\begin{array}{l}162 \\
165 \\
167 \\
172 \\
160 \\
172 \\
175 \\
172 \\
170 \\
168\end{array}$ & $\begin{array}{l}3 \cdot 90 \\
4 \cdot 45 \\
4 \cdot 00 \\
4 \cdot 15 \\
3 \cdot 50 \\
4 \cdot 30 \\
4 \cdot 60 \\
4 \cdot 40 \\
4 \cdot 40 \\
4 \cdot 20\end{array}$ & $\begin{array}{l}5 \cdot 47 \\
5 \cdot 76 \\
5 \cdot 29 \\
5 \cdot 40 \\
4 \cdot 01 \\
5 \cdot 38 \\
6 \cdot 93 \\
5 \cdot 49 \\
5 \cdot 07 \\
6 \cdot 64\end{array}$ & $\begin{array}{l}26 \cdot 4 \\
38 \cdot 0 \\
25 \cdot 0 \\
33 \cdot 7 \\
25 \cdot 7 \\
33 \cdot 7 \\
31 \cdot 1 \\
38 \cdot 2 \\
33 \cdot 8 \\
29 \cdot 6\end{array}$ & $\begin{array}{l}22 \cdot 5 \\
24 \cdot 8 \\
26 \cdot 0 \\
44 \cdot 1 \\
12 \cdot 5 \\
31 \cdot 7 \\
30 \cdot 2 \\
51 \cdot 2 \\
30 \cdot 8 \\
25 \cdot 7\end{array}$ & $\begin{array}{l}-68 \\
-80 \\
-88 \\
-96 \\
-70 \\
-107 \\
-78 \\
-123 \\
-72 \\
-84\end{array}$ & $\begin{array}{r}120 \\
86 \\
78 \\
113 \\
40 \\
65 \\
108 \\
115 \\
36 \\
69\end{array}$ \\
\hline
\end{tabular}

VC $=$ vital capacity; TLC =total lung capacity; Pst $(\mathrm{I})=$ static lung recoil pressure; Pdi=transdiaphragmatic pressure; Ppl=pleural pressure ${ }^{*} \mathrm{cmH}_{2} \mathrm{O} \times 0 \cdot 1=\mathrm{kPa}$.

of vital capacity and total lung capacity are given in the table.

All measurements were carried out with the subject in the sitting position. In each subject, several vital capacity manoeuvres and absolute lung volume measurements were made in a constant volume plethysmograph in order to determine residual volume (RV), functional residual capacity (FRC), and total lung capacity (TLC). We measured oesophageal and gastric pressures with balloon catheter systems coupled to pressure transducers. Each balloon was $10 \mathrm{~cm}$ long and $3.5 \mathrm{~cm}$ in diameter, and was attached to PE 200 tubing $100 \mathrm{~cm}$ in length. The oesophageal balloon was positioned in midoesophagus by the me.hod of Milic-Emili et al ${ }^{11}$; it contained $0.4 \mathrm{ml}$ air and was used as an index of pleural pressure $(\mathrm{Ppl})$. The gastric balloon was similar to the oesophageal balloon but somewhat thicker walled; it was positioned $65 \mathrm{~cm}$ from the nares to the balloon tip and contained $20 \mathrm{ml}$ of air. It was used as an index of abdominal pressure ( $\mathrm{Pab}$ ) according to the method of Agostoni and Rahn. ${ }^{1}$ The pressure on the abdominal side of the diaphragm was obtained by subtracting from gastric pressure an amount sufficient to make it identical to oesophageal pressure at resting end-expiration (FRC). Transdiaphragmatic pressure (Pdi) was derived from the signals of $\mathrm{Pab}$ and $\mathrm{Ppl}$ electrically according to the equation $\mathrm{Pdi}=\mathrm{Pab}-\mathrm{Ppl}$. Lung volume (V) was plotted against Pdi on a direct-writing $\mathrm{X}-\mathrm{Y}$ recorder. It was plotted simultaneously against $\mathrm{Ppl}$ and Pab on the $\mathrm{X}$ and $\mathrm{Y}$ axes of a $X \mathrm{X}^{\prime}-\mathrm{Y}$ storage oscilloscope.

Inspiratory and expiratory pressure-volume (PV) curves of the lung were obtained by a quasistatic method ${ }^{12}$; both inspiratory and expiratory flows were kept constant at $0 \cdot 1-0 \cdot 2$ litre/s. The procedure was repeated in each subject until PV data were closely reproducible - that is, agreed to $\pm 1 \mathrm{cmH}_{2} \mathrm{O}$ in at least three successive recordings. The PV curve of the lung, including the lung recoil pressure (Pst(1)) at full inflation, in each of the 20 subjects examined agreed well with the normal values recently published from our laboratory. ${ }^{13} 14$ When familiar with the equipment, the subject was instructed to repeat the manoeuvre of slow inflation. Pressure-volume data were then obtained with all pressures (Ppl, Pab, and Pdi) recorded simultaneously. Here again, the inspiratory flow was kept constant at $0 \cdot 1-0.2$ litre/s. All tracings in which flow was either too fast or uneven were rejected. The procedure was repeated at least three times, with an appropriate delay between repetitions to allow checking of the two balloons. Any tracings with an inspiratory capacity that was not within $5 \%$ of the largest inspiratory capacity obtained just before the tests were discarded.

Pleural, abdominal, and transdiaphragmatic 
pressures were also obtained during repeated maximal inspiratory efforts performed against a closed shutter. A conventional mouthpiece and noseclip were used, and pressures sustained for one second were recorded. ${ }^{14}$ After some practice attempts, once familiar with the manoeuvre, each individual developed pleural pressures that, at a given lung volume, did not vary by more than $10 \%$. At least 15 correctly executed manoeuvres were recorded on each subject at different lung volumes betwen FRC and TLC, and at each lung volume the lowest recorded value of $\mathrm{Ppl}$ was used for analysis. Maximal static pressure-volume curves were fitted by eye to the measured pressure and volume points. Lung volume was not corrected for gas rarefaction.

It must be stressed that, during these two types of respiratory manoeuvre, unless specifically stated otherwise, no instructions were given to the subjects regarding how to perform the manoeuvre. Thus, each subject was free to use his diaphragm or his intercostal/accessory muscles, or both, to execute it. None of the subjects was aware of the slopes of the curves he had to generate, and the tracings were not within the subject's view during the experiment.

\section{Results}

The behaviour of Pab during the course of a maximal inspiration was highly reproducible in each individual-that is, was superimposed in the three or more repeated efforts performed by the subject. It was, however, quite variable between individuals. Considering the 20 subjects examined, three quite different patterns may be defined and these are illustrated by the examples shown in fig 1. Ten of the subjects had a pattern grossly similar to that seen in subject 10 (fig 1, upper panel), ie, Pab progressively increased during inspiration. Accordingly, the total pressure exerted by the diaphragm (Pab-Ppl) during the inspiratory capacity manoeuvre also increased with increasing lung volume. In the table we have listed the Pst (1) and Pdi values at TLC for each subject. These values are averages for the last two to three seconds of the inspiratory phase at which time pressures were maintained at steady levels. In these 10 subjects, the Pdi achieved at full inflation was higher than the corresponding lung recoil pressure. By contrast, in seven of the subjects, $\mathrm{Pab}$ remained approximately equal to the value at resting end-expiratory volume and thus, was less than atmospheric throughout inspiration (fig 1, middle panel); these subjects had at TLC

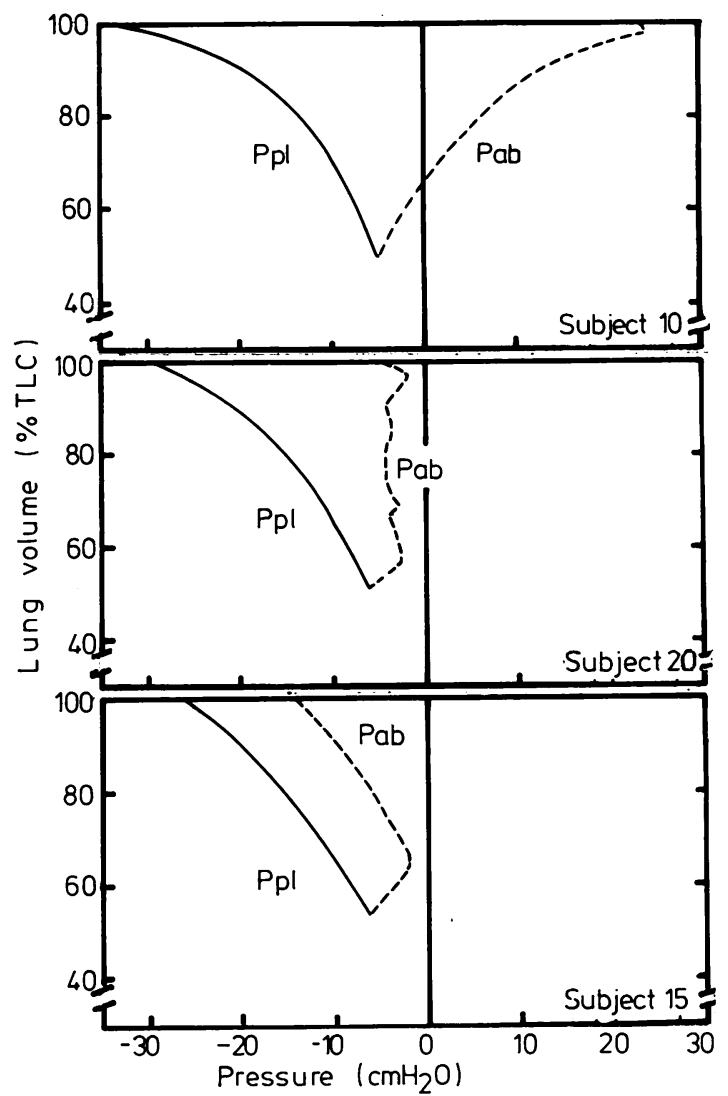

Fig 1 Records of pleural pressure (Ppl, solid line) and abdominal pressure (Pab, dashed line) during a full inspiration in three normal subjects. Each line represents the mean of at least three tracings. The horizontal distance between the continuous and broken lines represents the transdiaphragmatic pressure. $\mathrm{cmH}_{2} \mathrm{O} \times 0 \cdot 1=k P a$.

a value of Pdi that was close to the lung recoil pressure (table). Finally, three of the subjects $(5,12$, and 15) showed a Pab that became more and more negative during the course of the maximal inspiration (fig 1, lower panel). Accordingly, the Pdi was clearly lower than the lung recoil pressure at any lung volume, including at full inflation (table). After instruction to enhance abdominal motion during inspiration, however, these subjects were able to increase their Pdi at TLC to $56 \cdot 5,63 \cdot 4$, and $46 \cdot 2 \mathrm{cmH}_{2} \mathrm{O}$ respectively, indicating substantial reserve of the diaphragm as a pressure generator.

The individual values of Ppi obtained at $60 \%$ TLC during maximal static inspiratory efforts are 
given in the table. The behaviour of Pab during such manoeuvres also differed markedly between subjects. This interindividual variation is illustrated in fig 2, in which the values of Ppl (closed circles) and Pab (open circles) obtained at different lung volumes in three subjects are shown. The values of Ppl during the maximal static inspiratory efforts are similar to those obtained in a previous study. ${ }^{14}$ In agreement with the previous observations, ${ }^{12} 14$ the pleural pressure during these efforts declined with increasing lung volume. By contrast only a relatively small proportion of the subjects exhibited the "general" pattern described by Milic-Emili et $a l,{ }^{2}$ in which Pab during maximal static inspiratory efforts is about the same as during relaxation at all lung volumes (fig 2 , middle panel). Several subjects developed relatively high Pab at all lung volumes (fig 2, upper panel) and in five subjects, Pab was markedly subatmospheric at all lung volumes (fig 2, lower panel). Here again, the pattern was remarkably constant in each indi- vidual subject, as indicated by the narrow scatter of the data points.

Figure 3 shows the maximum static Pdi obtained at various lung volumes in the 20 subjects examined. It is quite clear from this graph that there existed a very large interindividual variability in the Pdi values obtained during maximal static inspiratory efforts. It is also clear from these data that at least seven of our subjects would have been considered as having disturbed diaphragm function when compared with the values recently reported from normal subjects by Gibson et al. ${ }^{10}$ These subjects with low Pdi values during maximal static inspiratory efforts had however a normally functioning diaphragm. For example, subjects 5 and 9 , who naturally during 은 the manoeuvre developed clearly negative values of $\mathrm{Pab}$, were able after a few practice attempts to increase their Pdi from 18 to $110 \mathrm{cmH}_{2} \mathrm{O}$, and from 42 to $121 \mathrm{cmH}_{2} \mathrm{O}$, respectively at $60 \%$ TLC.

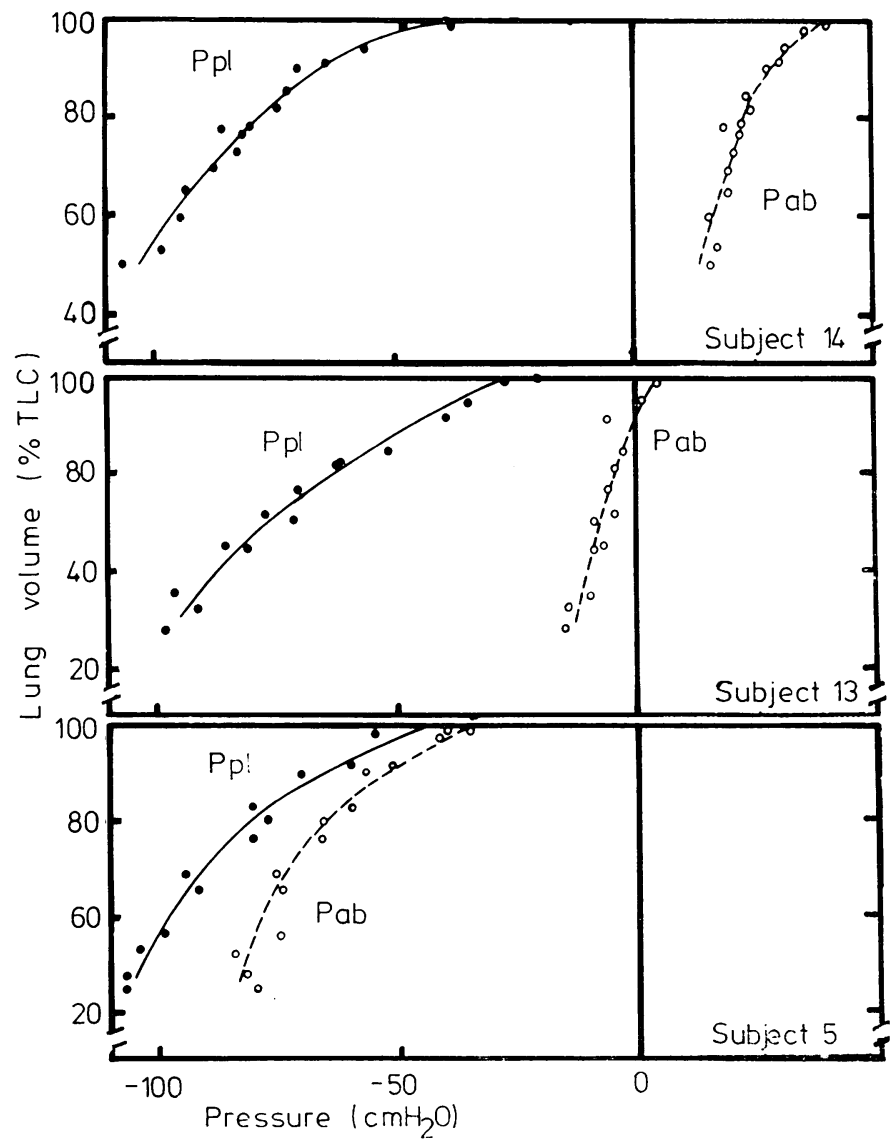

Fig 2 Records of pleural pressure (closed circles, solid line) and abdominal pressure (open circles, broken line) during repeated maximum static inspiratory efforts at various lung volumes in three normal subjects. $\mathrm{cm} \mathrm{H}_{2} \mathrm{O} \times 0 \cdot 1=k P a$. 


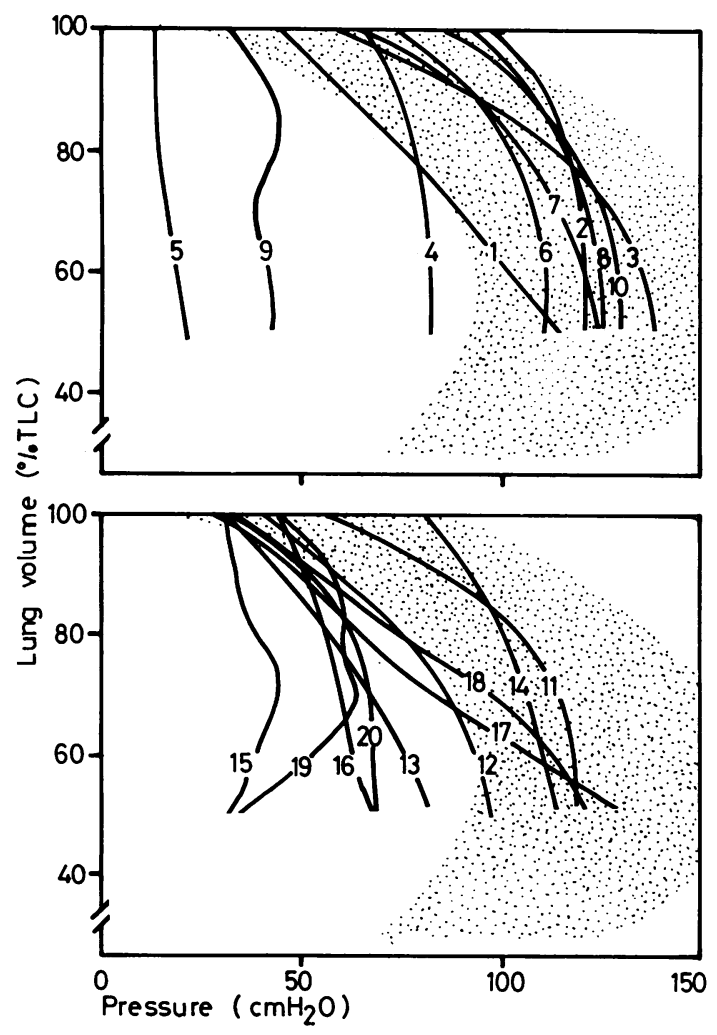

Fig 3 Maximum static transdiaphragmatic pressures during forced inspiratory efforts at various lung volumes in 10 healthy men (upper panel) and 10 healthy women (lower panel), 22-36 years of age. Lines fitted by eye. Shaded area represents values reported from seven normal subjects by Gibson et al. ${ }^{10}$ $\mathrm{cmH}_{2} \mathrm{O} \times 0 \cdot 1=k P a$.

\section{Discussion}

Our results show clearly that during a full, slowly performed, inspiration there is a large variation between subjects in the pattern of pressure generation, an observation which Mead et al have also made in elucidating the factors determining the position of full inflation in human subjects. ${ }^{15}$ Although we do not believe that the data in fig 1 can be quantified in terms of the pressure contributed by the intercostal/accessory m: Is:les, ${ }^{16} \mathrm{wc}$ can make qualitative statements about the relative contributions of the various muscle groups to the respiratory pressure swings. The lack of increase in Pab during inspiration signals recruitment of intercostal and accessory muscles of inspiration, and a fall in Pab during inspiration below its resting end-expiratory value indicates strong recruitment of intercostal and accessory muscles with upward displacement of the diaphragm. Of considerable clinical relevance is the finding that some of our healthy subjects showed such a recruitment of the rib cage muscles during successive maximal inspirations from FRC to TLC that they did not develop as little as $25 \mathrm{cmH}_{2} \mathrm{O}$ transdiaphragmatic pressure, which is the value usually considered as being the normal lower limit. ${ }^{67}$ It is concluded from this that assessing diaphragm function on the basis of the Pdi achieved at TLC may be quite hazardous and will often lead to misinterpretation. For example, some individuals, because they naturally use their intercostal and accessory muscles during the course of a maximal inspiration (fig 1, lower panel), will achieve very low Pdi at TLC (eg, $10 \mathrm{cmH}_{2} \mathrm{O}$ ) despite normal diaphragm. Conversely, patients with generalised muscle weakness and severely compromised diaphragm occasionally will develop values as high as $40 \mathrm{cmH}_{2} \mathrm{O}$ because they are "diaphragmatic breathers," either naturally or as a result of extensive involvement of the intercostal musculature.

Similar considerations may be developed regarding the Pdi values recorded during maximal static inspiratory efforts. Milic-Emili et al had previously observed that during such manoeuvres made by 6 tiained subjects the Pab was consistenly close to that seen during voluntary relaxation. ${ }^{2}$ In fact, only some of our subjects reproduced the pattern described by those workers (fig 2 , middle panel). A substantial number of our subjects developed high $\mathrm{Pab}$ at all lung volumes, presumably as a result of antagonistic contraction of the abdominal muscles, while others exhibited strong recruitment of the intercostal and accessory muscles of inspiration. These observations make it clear that the natural pattern of respiratory muscle contraction during maximal static inspiratory efforts varies over a wide range among untrained individuals, and also that it is unreasonable to compare measurements of Pdi of such subjects with those of highly trained respiratory physiologists. In addition, as illustrated in fig 3 , they indicate that, just as in the case of maximal inspirations from FRC to TLC, it is unwise to label a single individual as abnormal on the basis of Pdi values recorded during forceful inspiratory manoeuvres performed against an occluded airway. In quite a few patients - that is those who inspire maximally and forcefully with no pressure difference between the two sides of the diaphragm (Pdi is zero) and who will thus be recognised as having total dia- 
phragmatic paralysis-a correct diagnosis may be obtained with this method.

These considerations do not invalidate the usefulness of transdiaphragmatic pressure measurement in the evaluation of diaphragm function. They emphasise the necessity of keeping in mind the fundamental, but often overlooked, point that Pdi, as usually obtained, is a reflection of the behaviour of the diaphragm, not of its efficiency as a pressure generator. For this approach to ensure an accurate assessment of diaphragm function, it appears essential to standardise the testing conditions carefully in order to avoid falsepositive results in normal subjects and falsenegative results in patients. Two possibilities come to mind. Grassino and associates ${ }^{3}$ have shown that the Pdi developed at any given electrical stimulation is markedly related to the chest wall or diaphragmatic configuration. This approach might have much practical value. Only one would need to monitor the abdominothoracic configuration together with lung volume and changes in oesophageal and gastric pressure. By measuring the relationship between the volume of rib cage and abdomen and the Pdi at different lung volumes in a group of healthy subjects, a series of standard isopleths relating to Pdi to chest wall configuration at different constant lung volumes might be constructed. The observation in a given subject of a decrease in Pdi from the predicted value for a given chest wall configuration in the appropriate isopleth will be indicative of diaphragmatic weakness or paralysis. Another way of improving the reliability of Pdi measurement would be to standardise the pattern of inspiratory pressure swings. A uniform pattern of respiratory muscle contraction seems relatively difficult to achieve in untrained patients during a full inflation as well as during any respiratory effort. For practical purposes, however, the diaphragmatic Mueller manoeuvre-that is, a maximal static inspiratory effort with maximal outward motion of the abdomen-could be used and in our experience most subjects would have little difficulty in mastering the manoeuvre after a few practice attempts. On theoretical grounds, both methods should allow the Pdi measurement to give a reliable estimate of diaphragmatic function, but their value in daily clinical practice has yet to be determined.

\section{References}

1 Agostoni E, Rahn H. Abdominal and thoracic pressures at different lung volumes. $J$ A ppl Physiol 1960; 15:1087-92.

2 Milic-Emili J, Orzalesi MM, Cook CD, Turner JM. Respiratory thoraco-abdominal mechanics in man. J A ppl Physiol 1964; 19:217-23.

3 Grassino A, Goldman MD, Mead J, Sears TA. Mechanics of the human diaphragm during voluntary contraction: statics. J A ppl Physiol 1978; 44:829-39.

4 Goldman MD, Mead J. Mechanical interaction between the diaphragm and rib cage. J Appl Physiol 1973; 35:197-204.

5 Roussos C, Fixley M, Gross D, Macklem PT. Fatigue of inspiratory muscles and their synergic behavior. J A ppl Physiol 1979; 46:897-904.

6 Loh L, Goldman M, Newsom Davis J. The assessment of diaphragm function. Medicine (Baltimore) 1977; 56:165-9.

7 Newsom Davis J, Goldman M, Loh L, Casson M. Diaphragm function and alveolar hypoventilation. $Q J$ Med 1976; 45:87-100.

8 Gibson GJ, Pride NB, Newsom Davis J, Loh LC. Pulmonary mechanics in patients with respiratory muscle weakness. Am Rev Respir Dis 1977; 115: 389-95.

9 Kreitzer SM, Saunders NA, Tyler HR, Ingram RH Jr. Respiratory muscle function in amyotrophic lateral sclerosis. Am Rev Respir Dis 1978; 117:437-47.

10 Gibson GJ, Edmonds JP, Hughes GRV. Diaphragm function and lung involvement in systemic lupus erythematosus. Am J Med 1977; 63:926-32.

11 Milic-Emili J, Mead J, Turner JM, Glauser EM. Improved technique for estimating pleural pressure from esophageal balloons. J A ppl Physiol 1964; 19:207-11.

12 De Troyer A, Yernault JC, Englert M, Baran D, Paiva M. Evolution of intrathoracic airway mechanics during lung growth. J Appl Physiol 1978; 44:521-7.

13 Yernault JC, De Troyer A, Rodenstein D. Sex and age differences in intrathoracic airway mechanics. J Appl Physiol 1979; 46:556-64.

14 De Troyer A, Yernault JC. Inspiratory muscle force in normal subjects and in patients with interstitial lung disease. Thorax 1980; 35:92-100.

15 Mead J, Milic-Emili J, Turner JM. Factors limiting depth of a maximal inspiration in human subjects. J Appl Physiol 1963; 18:295-6.

16 Macklem PT, Gross D, Grassino A, Roussos C. Partitioning of inspiratory pressure swings between diaphragm and intercostal/accessory muscles. J Appl Physiol 1978; 44:200-8. 